\title{
Giant paraesophageal hernia: What do we really know?
}

Amit Bhargava, MD, and Rafael Andrade, MD

Feature Editor Note-The management of giant paraesophageal hernias remains challenging. In this invited expert opinion article, Bhargava and Andrade provide an in-depth discussion of the controversies surrounding repair of giant paraesophageal hernias, including management of recurrent hiatal hernias, esophageal-lengthening procedures, and the use of mesh. Based on their own practice, they suggest performing an extensive mediastinal dissection to achieve adequate intra-abdominal esophageal length, gastroplasty when needed for esophageal shortening, and the avoidance of mesh due to the risk of erosion, cost, and lack of clear data supporting its use. Other practices are more controversial, such as placement of a gastrostomy tube for recurrent hernias in the hopes of preventing recurrence, avoidance of a fundoplication in patients with morbid obesity, and usage of a pharyngostomy tube for decompression, which is considered a legacy procedure by most surgeons.

Recurrent paraesophageal hernias in particular require a thoughtful approach, including obtaining the operative report from the initial operation when possible, considering the severity of the patient's symptoms, and careful review of objective data from current studies. Patients with multiple previous repairs are unlikely to benefit from a repeat repair, and partial gastrectomy with Roux-en-Y esophagojejunostomy or esophagectomy should be reserved for those with severe symptoms such as the inability to tolerate an oral diet.

The authors emphasize the importance of clearly defining what constitutes a giant paraesophageal hernia, the natural history, and an objective assessment of short- and long-term outcomes. While there have been substantial advances, repair of a giant paraesophageal hernia continues to be a challenging procedure, particularly redo repair, and should be performed in experienced, high-volume centers.

\section{Jules Lin, MD}

In 1919, Soresi performed the first operation to reduce a hiatal hernia and to approximate the crura. ${ }^{1}$ Over the past 100 years, Nissen, Collis, Skinner, and Maziak advanced

\footnotetext{
From the Division of Thoracic and Foregut Surgery, Department of Surgery, University of Minnesota, Minneapolis, Minn.

Received for publication June 10, 2020; revisions received June 10, 2020; accepted for publication Aug 10, 2020; available ahead of print Aug 13, 2020.

Address for reprints: Rafael Andrade, MD, Division of Thoracic and Foregut Surgery, Department of Surgery, University of Minnesota, 420 Delaware St, SE, MMC 207,

Minneapolis, MN 55455 (E-mail: andr0119@umn.edu).

JTCVS Techniques 2020;3:367-72

2666-2507

Copyright (C) 2020 The Authors. Published by Elsevier Inc. on behalf of The American Association for Thoracic Surgery. This is an open access article under the CC BY-NCND license (http://creativecommons.org/licenses/by-nc-nd/4.0/).

https://doi.org/10.1016/j.xjtc.2020.08.021
}

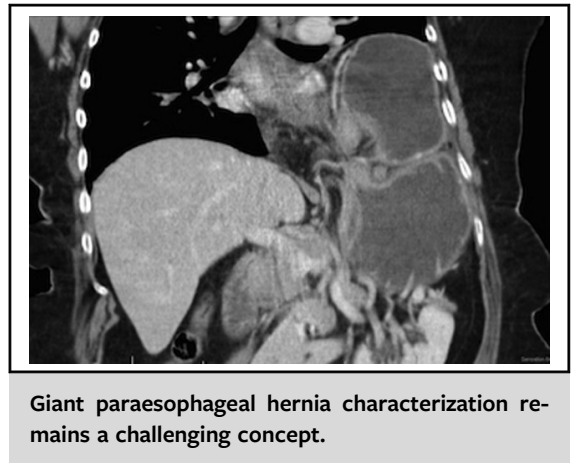

\begin{abstract}
CENTRAL MESSAGE
Laparoscopic giant paraesophageal hernia repair remains in evolution. We use extensive mediastinal dissection to achieve intra-abdominal esophageal length, gastroplasty as needed, and avoid mesh.
\end{abstract}

See Commentary on page 373 .

the field with their conceptual and technical innovations. ${ }^{2-5}$ In 1998, the first completely laparoscopic operation with a Collis gastroplasty and Nissen fundoplication was described. ${ }^{6}$ The laparoscopic approach is now the standard of care, with reduced perioperative morbidity and shorter hospital stays but similar long-term outcomes when compared with open techniques. ${ }^{7-10}$ Despite this long history, the surgical management of giant paraesophageal hernia (GPEH) remains in evolution, with several issues that remain to be clarified: (1) What is a GPEH? (2) Do all patients with GPEH need surgery? (3) Can we temporize patients with GPEH incarceration before definitive repair? (4) What is the role of fundoplication in repair of a GPEH? (5) How does mesh fit into repair of GPEH? (6) What constitutes the optimal postoperative strategy? (7) How do we best assess long-term outcomes?

\section{DEFINITION OF GPEH}

The term "giant paraesophageal hernia" is imprecise. The term "giant" is subject to interpretation, as there is no consensus on whether a $30 \%$ or a $50 \%$ herniation of the stomach should be defined as giant. The term 
"paraesophageal hernia" further contributes to confusion, since it is applicable to type II or III hiatal hernias. In summary, a GPEH is a hiatal hernia with displacement of at least $30 \%$ of the stomach along the long axis of the esophagus, with or without cephalad displacement of the gastroesophageal junction.

\section{INDICATIONS FOR SURGICAL TREATMENT OF GPEH}

While a sliding hiatal hernia can be managed nonoperatively in the absence of symptoms, it is less clear that GPEH can be left alone once discovered. ${ }^{7}$ In addition, very few patients are truly asymptomatic if they have a GPEH; they are more likely to be accustomed to symptoms than to be asymptomatic. The natural history of GPEH is illdefined; one Finnish study showed an in-hospital mortality of $16.4 \%$ in patients with paraesophageal hernia treated with conservative therapy. ${ }^{11}$ Other studies endeavored to compare watchful waiting versus elective laparoscopic repair and concluded that patients would benefit more from watchful waiting. ${ }^{12,13}$ At this point, we can make some recommendations based on what we understand about GPEH. First, symptomatic GPEH warrants consideration of surgical treatment since symptoms will only worsen with time; second, a patient with a GPEH and crescendo symptoms requires surgical repair in the short term because it may portend an incarceration; third, a patient with an incarcerated or strangulated GPEH needs urgent intervention; fourth, patients with type II hiatal hernia, regardless of size, should be treated surgically whenever possible; and, fifth, patients with minimal or no symptoms should be considered for surgical repair, but with limited understanding of the natural history of untreated GPEH, we allow room for individualization and conservative management with regular follow-up. As a reflection of these heterogeneous indications for surgery, the Society of American Gastrointestinal and Endoscopic Surgeons (SAGES) guideline suggests careful evaluation on an individual-case basis. ${ }^{7}$

\section{ROLE OF TEMPORIZING MEASURES IN PATIENTS WITH INCARCERATED GPEH}

Patients with incarcerated GPEH always require an intervention to manage symptoms and prevent strangulation. The question is what intervention? We know that emergent repair of hiatal hernia is associated with greater morbidity and mortality than elective repair, and that these patients tend to be older, frailer, weigh less, and have more comorbidities than patients who undergo elective repair. ${ }^{12,14} \mathrm{We}$ guide the treatment of these patients primarily by age, comorbidities, and nutritional status. Patients without malnutrition or severe comorbidities can be treated with primary laparoscopic repair of GPEH upon presentation. We treat very elderly, frail, and malnourished patients differently. We first proceed with urgent endoscopic and fluoroscopic decompression, nasogastric tube placement in the operating room, and establish a nutritional support plan. Total parenteral nutrition is adequate for short-term nutritional needs, but we place a surgical jejunostomy feeding tube in chronically malnourished patients. These patients will likely require nutritional support for some time even after surgical repair of the GPEH. Once a patient has been acutely decompressed and temporized, we decide whether to repair the GPEH during the same hospitalization or a few weeks later with improved nutritional status. For the small subset of high-risk patients that we treat with decompression first and delay repair by several weeks, we provide long-term decompression via a pharyngostomy tube if necessary. ${ }^{15}$ After several weeks and reassessment of patient status in clinic, we schedule a primary repair electively. To date, there are no data to guide therapy in this subset of patients, but adhering to the principle of preoperative nutritional optimization seems reasonable. Over an 8-year period, we have treated 9 of 14 patients admitted with an acute, incarcerated, nonstrangulated hernia with a temporizing approach. The median age was 72 years, all patients had below-normal albumin levels on presentation, and all had major comorbidities. Despite the preoperative precautions, the morbidity rate was $33 \%$ and the 30-day mortality rate $11 \%$.

\section{PRINCIPLES OF SURGICAL REPAIR OF GPEH}

The general principles of repair of GPEH have remained the same over the years. In summary, to reduce the hernia sac; to undertake extensive mediastinal dissection, with preservation of the vagus nerves, to ensure adequate intraabdominal esophageal length; to perform a gastroplasty only if necessary for additional esophageal length and after extensive mediastinal mobilization; to repair the crura with preservation of the crural peritoneal covering; and, often, to perform a fundoplication. We perform circumferential esophageal mediastinal dissection at least to the level of the inferior pulmonary veins. Mobilization also includes dissection of all gastric attachments to the diaphragm to facilitate tension-free primary closure of the hiatus.

\section{THE ROLE OF FUNDOPLICATION IN REPAIR OF A GPEH}

The role of fundoplication in patients with GPEH is not entirely clear. We know there is a link between gastroesophageal reflux disease (GERD) and hiatal hernia ${ }^{7,16}$ but not whether a fundoplication should be performed on every patient with a GPEH. A randomized controlled trial evaluated the addition of a Nissen fundoplication to a PEH repair. While there was some benefit to a fundoplication with respect to postoperative reflux symptoms, it is not clear how many patients had GPEH. Further, all 40 patients had a mesh repair, with a circular polypropylene mesh and were randomized to a cardiophrenicopexy or 
fundoplication, fashioned over a 56-Fr bougie with no routine division of the short gastric arteries. ${ }^{17}$ This was a small study, and the generalizability is unclear. There are several nuances when considering the need for a fundoplication. We generally perform a fundoplication in younger patients ( $<70$ years) and patients with heartburn and regurgitation. A fundoplication in elderly patients and in patients who complain mainly of dysphagia is possibly not necessary, but we do not have data to guide us with that decision. We tend to avoid fundoplication in patients with morbid obesity, because hernia recurrence appears to be greater in this population. ${ }^{18}$ In addition, a herniated Nissen fundoplication generally causes severe dysphagia and pain and often requires reoperation.

\section{OBESITY AND PARAESOPHAGEAL HERNIAS}

For patients with a body mass index (BMI) in the 30 to 35 range, we recommend weight loss as an initial step to prevent greater recurrence rates. In patients with BMI $>35$, we refer the patients for evaluation for Roux-en-Y gastric bypass operations. Sleeve resections can lead to lower lower-esophageal sphincter pressures and greater intragastric pressures, leading to new reflux after surgery. ${ }^{19}$ The 5 -year incidence of symptomatic GERD after sleeve resection ranges from $18 \%$ to $31 \%{ }^{19-22}$ Roux-en-Y gastric bypass seems to be a better operation in this context, with significant improvements in GERD-related symptoms in multiple studies. ${ }^{23-25}$ For patients with a BMI $\geq 35$ who do not undergo gastric bypass, we perform a repair preferably without Nissen fundoplication.

\section{THE ROLE OF MESH IN GPEH REPAIR}

We believe that permanent mesh should never be used since it can erode into the esophagus or stomach and lead to severe morbidity. ${ }^{26}$ One clinical trial evaluated the use of biologic mesh in hiatal hernia repair versus no mesh. ${ }^{27}$ Although results at 6 months were encouraging, follow-up at 5 years showed no difference in recurrence rates between both groups, which were as high as $59 \%$ (primary repair group vs $54 \%$ in the biologic mesh group), but reoperation was only required in $3.5 \%$ in the primary repair group and none in the biologic mesh group. ${ }^{27}$ In a retrospective review with 106 patients who had a mesh (various types) cruroplasty and 689 with suture alone, there was no difference in postoperative symptoms, and radiographic recurrence rates were similar between the 2 groups. However, reoperations for recurrence were greater in the mesh group $(9 \%$ vs $3 \%$ in the suture group, $P=.01) .{ }^{28}$ Despite studies like these, the appetite for using mesh remains strong. A survey of more than 500 European surgeons showed that $67 \%$ of them used mesh in hiatal hernia repairs, with $67 \%$ of those preferring synthetic mesh over biologic. Fully one fifth of the surgeons had encountered mesh erosion at some point during their career. ${ }^{29}$ The authors almost never use mesh, because there is no evidence to support its use and because it is costly.

\section{ESOPHAGEAL-LENGTHENING PROCEDURES}

When there is $\leq 2 \mathrm{~cm}$ of intra-abdominal esophagus, we perform a wedge Collis gastroplasty. First, we confirm that the maximal extent of mediastinal dissection has been done. The assessment of intra-abdominal esophageal length is done with the stomach under no traction. We pass an endoscope to assess the location of the gastroesophageal junction. If there is not enough length, we pass a 54French dilator under laparoscopic vision. We fashion a wedge gastroplasty by using serial stapler fires to create a snug 2- to 3-cm neoesophagus. The downside to any lengthening procedure, particularly in conjunction with a fundoplication, is that acid-producing cells are then part of the neoesophagus. A large study compared patients who underwent GPEH repair with Collis gastroplasty and fundoplication $(\mathrm{n}=454)$ with a group that underwent fundoplication alone $(\mathrm{n}=341)$. Both cohorts had similar outcomes for radiographic recurrence and quality of life improvements, assessed by the GERD-Health Related Quality of Life Questionnaire and the Medical Outcomes Study Short Form 36. Although the Collis gastroplasty group had statistically significantly improved pain resolution and less gas bloat, the clinical relevance of this finding in a retrospective series is unclear. ${ }^{30}$ Table 1 shows short- to medium-term results of laparoscopic GPEH repair with a gastroplasty. ${ }^{6,30-34}$

\section{POSTOPERATIVE STRATEGY}

Patients who undergo GPEH repair and a fundoplication should be treated following postoperative fundoplication principles of gradual diet progression, prevention of postoperative nausea and vomiting, and prevention of postoperative constipation. However, patients with GPEH may struggle with postoperative delayed gastric emptying, and we suggest gastric decompression with a nasogastric tube for at least 12 to 24 hours and close monitoring of the gastric bubble with chest radiographs. A key cause for morbidity in frail, elderly patients is a respiratory complication. These patients may take longer to recover their gastric-emptying function and are prone to aspiration regardless of gastric emptying. In this high-risk population, irrespective of presence or absence of fundoplication, we use a temporary gastrostomy tube for decompression and remove it 4 to 6 weeks later. The risk and morbidity of a respiratory complication far outweighs the risk and morbidity of a gastrostomy tube. Although we have no data to demonstrate that gastrostomy tubes prevent respiratory complications in this population, we strongly believe they provide an extra tool for the management of these high-risk patients. 
TABLE 1. Laparoscopic repair GPEH with gastroplasty

\begin{tabular}{|c|c|c|c|c|c|c|}
\hline & $\begin{array}{l}\text { Swanstrom } \\
\text { et al, } 1996^{31} \\
\end{array}$ & $\begin{array}{c}\text { Johnson } \\
\text { et al, } \mathbf{1 9 9 8}^{6} \\
\end{array}$ & Jobe et al, $1998^{32}$ & Lin et al, $2004^{33}$ & $\begin{array}{c}\text { Whitson } \\
\text { et al, } \mathbf{2 0 0 6}^{34}\end{array}$ & $\begin{array}{c}\text { Nason } \\
\text { et al, } \mathbf{2 0 1 1}^{30}\end{array}$ \\
\hline Technique & $\begin{array}{l}\text { Collis with } \\
\text { Nissen } \\
\text { (VATS- } \\
\text { assisted) }\end{array}$ & $\begin{array}{l}\text { Collis with } \\
\text { Nissen }\end{array}$ & $\begin{array}{l}\text { Collis with } \\
\text { Nissen }\end{array}$ & $\begin{array}{l}\text { Collis with } \\
\text { Nissen }\end{array}$ & $\begin{array}{l}\text { Collis with } \\
\text { Nissen }\end{array}$ & $\begin{array}{l}\text { Collis with } \\
\text { Nissen, } \\
\text { (EEA vs } \\
\text { wedge) }\end{array}$ \\
\hline Patients, $\mathrm{n}$ & 3 & 9 & 15 & $\begin{array}{l}68 \text { (56 } \\
\quad \text { laparoscopic) }\end{array}$ & 61 & 454 \\
\hline OR time, $\min$ & $257^{*}$ & $297 *$ & $252 *$ & - & $274 \dagger$ & $229 \dagger$ \\
\hline Morbidity, \% & 0 & 22 & 15 & - & 8 & 20 \\
\hline Mortality, \% & 0 & 0 & 0 & - & 1.7 & 1.5 \\
\hline Follow-up, mo & $8 *$ & - & $14 *$ & $30 *$ & $18 \dagger$ & $36 \dagger$ \\
\hline Follow-up evaluation & $\begin{array}{l}\text { Endoscopy, } \\
\text { 24-h pH, } \\
\text { manometry, } \\
\text { symptoms }\end{array}$ & $\begin{array}{l}\text { Endoscopy, } \\
\text { symptoms }\end{array}$ & $\begin{array}{l}\text { Endoscopy with } \\
\text { biopsy, 24-h pH, } \\
\text { manometry, } \\
\text { symptoms }\end{array}$ & $\begin{array}{l}\text { Endoscopy, } \\
\text { 24-h pH, } \\
\text { esophagram }\end{array}$ & $\begin{array}{c}\text { Esophagram, } \\
\text { symptoms }\end{array}$ & $\begin{array}{r}\text { Esophagram, } \\
\text { symptoms }\end{array}$ \\
\hline Postoperative heartburn, $\%$ & 0 & 11 & 14 & 14 & 11.6 & 28 \\
\hline Postoperative dysphagia, $\%$ & - & 11 & 14 & 11 & 27 & 37 \\
\hline Postoperative regurgitation, $\%$ & - & 0 & - & 9 & 7.7 & 11 \\
\hline Anatomic recurrence, $\%$ & 0 & 11 & 0 & 17 & 4.7 & 16.6 \\
\hline Patient satisfaction, $\%$ & 91 & - & 100 & 65 & 98 & 93 \\
\hline
\end{tabular}

VATS, Video-assisted thoracoscopic surgery; $E E A$, endoscopic endonasal approach; $O R$, operating room. *Mean value. $\dagger$ Median value.

\section{ASSESSMENT OF LONG-TERM OUTCOMES}

There is no good way to objectively measure a recurrence. In the only clinical trial on biologic mesh, the authors defined recurrence as a hernia of $\geq 2 \mathrm{~cm}$ as defined by 2 blinded radiologists, which is the generally accepted standard. Most groups, including us, use the definition of $2 \mathrm{~cm}$ of fundus above the hiatus or $>10 \%$ of the stomach. The usefulness of a strict radiologic definition in the absence of symptoms is questionable, unless it has some prognostic significance. A small radiologic recurrence in an 80-year-old patient is likely of less importance than in a 40-year-old patient, but we still do not know if it means that a patient will eventually develop a symptomatic recurrence. Based on these limitations, the most important parameters in long-term follow-up are symptoms and the need for reoperation. Symptoms can be assessed using validated questionnaires, such as the GERD-Health Related Quality of Life, which are useful in tracking outcomes. All major open transthoracic and laparoscopic series that follow the surgical principles of GPEH repair report good and durable symptom control (albeit without standardization) and a long-term reoperation rate of less than $5 \% .5,8,10,27,35-38$ Representative studies are depicted in Table 2. ${ }^{10,27,37-41}$

One thing that is clear is that GPEH operations, and in particular redo operations, are best done at high-volume centers. Schlottman and colleagues ${ }^{42}$ looked at a cohort of 63,812 patients who underwent PEH repair; $84 \%$ in high-volume, $11.9 \%$ in intermediate-volume (6-20 per year), and $4.1 \%$ in low-volume. This did include patients

TABLE 2. Outcomes after laparoscopic giant paraesophageal hernia repair

\begin{tabular}{|c|c|c|c|c|c|c|}
\hline Reference, $\mathbf{y}$ & $\mathbf{N}$ & $\begin{array}{l}\text { Follow-up, } \\
\text { mo, median }\end{array}$ & 30-d mortality, $\%$ & $\begin{array}{c}\text { Radiologic } \\
\text { recurrence, \% }\end{array}$ & $\begin{array}{c}\text { Redo } \\
\text { operation, \% }\end{array}$ & $\begin{array}{c}\text { Patient } \\
\text { satisfaction, \% }\end{array}$ \\
\hline Quinn et al, $2019^{39}$ & 178 & 35 & $\begin{array}{c}5.1 \\
\left(1.6^{* / 16.7 \dagger)}\right)\end{array}$ & 8.4 & 7.3 & 83.7 \\
\hline Antiporda et al, $2018^{40}$ & 202 & 7 & 0 & 34.2 & 4.9 & - \\
\hline Le Page et al, $2015^{37}$ & 455 & 32 & 0.9 & 35.6 & 4.8 & - \\
\hline Dallemagne et al, $2011^{38}$ & 85 & 118 & 0 & 66 & 0.8 & 90 \\
\hline Oelschlager et al, 2006, $2011^{27,41}$ & 72 & 58 & 1.9 & $59 \ddagger / 54 \S$ & $3.5 \ddagger / 0 \S$ & - \\
\hline Luketich et al, $2010^{10}$ & 662 & 30 & 1.7 & 15.7 & 3.2 & 89 \\
\hline
\end{tabular}

*Elective procedure. $\dagger$ Emergent procedure. $\ddagger$ Primary repair. $\S$ Biological mesh repair. 
who had undergone open repairs as well, but the study showed a significant increase in complications in lowvolume $(<6$ operations annually) and intermediatevolume (6-20 annually) hospitals as compared with the high-volume ( $>20$ operations annually) hospitals. They noted a "spontaneous centralization" of PEH repairs, which we believe should be encouraged. A second study reviewed 595 patients who underwent laparoscopic PEH repair and found that surgeon volume (high $>10$ operations annually) was predictive of recurrence. ${ }^{40}$

\section{RECURRENT PARAESOPHAGEAL HERNIA}

We advocate a thoughtful approach when considering reoperation. We obtain all of the preoperative studies as well as the operative report for the initial operation(s). We consider symptoms before the original operation, type and number of procedures performed before, current symptoms, and the results of current studies. In particular, we obtain a new computed tomography scan of the chest and sometimes a gastric-emptying study. Our preferred approach is laparoscopic. The first goal of the operation is to restore normal anatomy, by taking down the wrap, removing any crural sutures, and mobilizing the mediastinum. We often encounter little scar tissue in the mediastinum, a reflection of insufficient esophageal mobilization in the past. In our experience, there is no need for mesh, assuming the crura can hold stitches. The creation of a fundoplication depends on patient history, symptoms, anatomy, and comorbidities. We always place a temporary prophylactic gastrostomy tube in reoperative cases. Surgical options after 3 or more failed operations include a partial gastrectomy with Roux-en-Y esophagojejunostomy or esophagectomy.

\section{SUMMARY}

Patients with GPEH form a heterogeneous group, and we still have more questions than answers. Although we have used the past 100 years to become adept at repairing $\mathrm{GPEH}$, it is time we attempt to address our knowledge gaps.

\section{Conflict of Interest Statement}

The authors reported no conflicts of interest.

The Journal policy requires editors and reviewers to disclose conflicts of interest and to decline handling or reviewing manuscripts for which they may have a conflict of interest. The editors and reviewers of this article have no conflicts of interest.

\section{References}

1. Stylopoulos N, Rattner DW. The history of hiatal hernia surgery: from Bowditch to loparoscopy. Ann Surg. 2005;241:185-93.

2. Nissen R. A simple operation for control of reflux esophagitis. Schweiz Med Wochenschr. 1956;86(suppl 20):590-2.

3. Collis JL. An operation for hiatus hernia with short oesophagus. J Thorac Cardiovasc Surg. 1957; 14:768-88.
4. Skinner DB, Belsey RH. Surgical management of esophageal reflux and hiatus hernia. Long-term results with 1,030 patients. J Thorac Cardiovasc Surg. 1967;53:33-54.

5. Maziak DE, Todd TR, Pearson FG. Massive hiatus hernia. J Thorac Cardiovasc Surg. 1998;115:53-60; discussion 61-2.

6. Johnson AB, Oddsdottir M, Hunter JG. Laparoscopic Collis gastroplasty and Nissen fundoplication. A new technique for for the management of esophageal foreshortening. Surg Endosc. 1998;12:1055-60.

7. Kohn GP, Price RR, Demeester SR, Zehetner J, Muensterer OJ, Awad Z, et al. Guidelines for the management of hiatal hernia. Surg Endosc. 2013;27: 4409-28.

8. Antonoff MB, D’Cunha J, Andrade RS, Maddaus MA. Giant paraesophageal hernia repair: technical pearls. J Thorac Cardiovasc Surg. 2012;144:S67-70.

9. Nason KS, Luketich JD, Qureshi I, Keeley S, Trainor S, Awais O, et al. Laparoscopic repair of giant paraesophageal hernia results in long-term patient satisfaction and a durable repair. J Gastrointest Surg. 2008;12:2066-77.

10. Luketich JD, Nason KS, Christie NA, Pennathur A, Jobe BA, Landreneau RJ, et al. Outcomes after a decade of laparoscopic giant paraesophageal hernia repair. J Thorac Cardiovasc Surg. 2010;139:395-404.e1.

11. Sihvo EI, Salo JA, Räsänen JV, Rantanen TK. Fatal complications of adult paraesophageal hernia: a population-based study. J Thorac Cardiovasc Surg. 2009; 137:419-24.

12. Stylopoulos N, Rattner D. Paraesophageal hernia: when to operate? Adv Surg 2003;37:213-29.

13. Jung JJ, Naimark DM, Behman R, Grantcharov TP. Approach to asymptomatic paraesophageal hernia: watchful waiting or elective laparoscopic hernia repair? Surg Endosc. 2018;32:864-71.

14. Jennifer AK, Samuel S, Matthew YCL, Stanley JR, Jonathan TC. Morbidity and mortality associated with elective or emergency paraesophageal hernia repair. JAMA Surg. 2015;150:1094-6.

15. Rueth NM, Lee N, Groth SS, Stranberg SC, Maddaus MA, D’Cunha J, et al. Pharyngostomy tubes for gastric conduit decompression. J Thorac Cardiovasc Surg. 2010;140:373-6.

16. Fuller CB, Hagen JA, DeMeester TR, Peters JH, Ritter M, Bremmer CG. The role of fundoplication in the treatment of type II paraesophageal hernia. J Thorac Cardiovasc Surg. 1996;111:655-61.

17. Müller-Stich BP, Achtstätter V, Diener MK, Gondan M, Warschkow R, Marra F, et al. Repair of paraesophageal hiatal herniaseis a fundoplication needed? A randomized controlled pilot trial. J Am Coll Surg. 2015;221:602-10.

18. Bashir Y, Chonchubhair HN, Duggan SN, Memba R, Ul Ain Q, Murphy A, et al Systematic review and meta-analysis on the effect of obesity on recurrence after laparoscopic anti-reflux surgery. Surgeon. 2019;17:107-18.

19. Braghetto I, Csendes A, Lanzarini E, Papapietro K, Cárcamo C, Molina JC. Is laparoscopic sleeve gastrectomy an acceptable primary bariatric procedure in obese patients? Early and 5-year postoperative results. Surg Laparosc Endosc Percutaneous Tech. 2012;22:479-86.

20. Bohdjalian A, Langer FB, Shakeri-Leidenmühler S, Gfrerer L, Ludvik B, Zacherl J, et al. Sleeve gastrectomy as sole and definitive bariatric procedure: 5-year results for weight loss and ghrelin. Obes Surg. 2010;20:535-40.

21. Himpens J, Dobbeleir J, Peeters G. Long-term results of laparoscopic sleeve gastrectomy for obesity. Ann Surg. 2010;252:319-24.

22. Howard DD, Caban AM, Cendan JC, Ben-David K. Gastroesophageal reflux af ter sleeve gastrectomy in morbidly obese patients. SOARD. 2011;7:709-13.

23. Frezza EE, Ikramuddin S, Gourash W, Rakitt T, Kingston A, Luketich J, et al. Symptomatic improvement in gastroesophageal reflux disease (GERD) following laparoscopic Roux-en-Y gastric bypass. Surg Endosc. 2002;16: 1027-31.

24. Jones KB, Allen TV, Manas KJ, Mcginty DP, Wilder WM, Wadsworth ED. RouxY gastric bypass: an effective anti-reflux procedure. Obes Surg. 1991;1:295-8.

25. Madalosso CAS, Gurski RR, Callegari-Jacques SM, Navarini D, Mazzini G, Da Silva Pereira M. The impact of gastric bypass on gastroesophageal reflux disease in morbidly obese patients. Ann Surg. 2016;263:110-6.

26. Stadlhuber RJ, El Sherif A, Mittal SK, Fitzgibbons RJ Jr, Brunt LM, Hunter JG, et al. Mesh complications after prosthetic reinforcement of hiatal closure: a 28 case series. Surg Endosc. 2009;23:1219-26.

27. Oelschlager BK, Pellegrini CA, Hunter JG, Brunt ML, Soper NJ, Sheppard BC et al. Biologic prosthesis to prevent recurrence after laparoscopic paraesophageal hernia repair: long-term follow-up from a multicenter, prospective, randomized trial. J Am Coll Surg. 2011;213:461-8.

28. Tam V, Luketich JD, Levy RM, Christie NA, Awais O, Shende M, et al. Mesh cruroplasty in laparoscopic repair of paraesophageal hernias is not associated 
with better long-term outcomes compared to primary repair. Am J Surg. 2017; 214:651-6.

29. Huddy JR, Markar SR, Ni MA, Morino M, Targarona EM, Zaninotto G, et al. Laparoscopic repair of hiatus hernia: does mesh type influence outcome? A meta-analysis and European survey study. Surg Endosc. 2016;30:5209-21.

30. Nason KS, Luketich JD, Awais O, Abbas G, Pennathur A, Landreneau RJ, et al. Quality of life after collis gastroplasty for short esophagus in patients with paraesophageal hernia. Ann Thorac Surg. 2011;92:1854-61.

31. Swanstrom LL, Marcus DR, Galloway GQ. Laparoscopic Collis gastroplasty is the treatment of choice for the shortened esophagus. Am J Surg. 1996;171: 477-81.

32. Jobe BA, Horvath KD, Swanstrom LL. Postoperative function following laparoscopic Collis gastroplasty for shortened esophagus. Arch Surg. 1998; 133:867-74.

33. Lin E, Swafford V, Chadalavada R, Ramshaw BJ, Smith CD. Disparity between symptomatic and physiologic outcomes following esophageal lengthening procedures for antireflux surgery. J Gastrointest Surg. 2004;8:31-9.

34. Whitson BA, Hoang CD, Boettcher AK, Dahlberg PS, Andrade RS, Maddaus MA. Wedge gastroplasty and reinforced crural repair: important components of laparoscopic giant or recurrent hiatal hernia repair. J Thorac Cardiovasc Surg. 2006;132:1196-202.e3.

35. Altorki NK, Yankelevitz D, Skinner DB. Massive hiatal hernias: the anatomic basis of repair. J Thorac Cardiovasc Surg. 1998;115:828-35.

36. Patel HJ, Tan BB, Yee J, Orringer MB, Iannettoni MD. A 25-year experience with open primary transthoracic repair of paraesophageal hiatal hernia. J Thorac Cardiovasc Surg. 2004;127:843-9.
37. Le Page PA, Furtado R, Hayward M, et al. Durability of giant hiatus hernia repair in 455 patients over 20 years. Ann R Coll Surg Engl. 2015;97: $188-93$.

38. Dallemagne B, Kohnen L, Perretta S, Weerts J, Markiewicz S, Jehaes C. Laparoscopic repair of paraesophageal hernia: long-term follow-up reveals good clinical outcome despite high radiological recurrence rate. Ann Surg. 2011; 253:291-6.

39. Quinn MA, Geraghty AJ, Robertson AGN, Paterson-Brown S, Lamb PJ, Edinburgh Oesophago-Gastric Surgery Group. Long-term outcomes following surgical repair of giant paraoesophageal hiatus hernia. Surg Endosc. 2019;33:1846-53.

40. Antiporda M, Veenstra B, Jackson C, Kandel P, Daniel Smith C, Bowers SP. Laparoscopic repair of giant paraesophageal hernia: are there factors associated with anatomic recurrence? Surg Endosc. 2018;32:945-54.

41. Oelschlager BK, Pellegrini CA, Hunter J, Brunt ML, Soper NJ, Sheppard BC, et al. Biologic prosthesis reduces recurrence after laparoscopic paraesophageal hernia repair: a multicenter, prospective, randomized trial. Ann Surg. 2006; 244:481-90.

42. Schlottmann F, Strassle PD, Allaix ME, Patti MG. Paraesophageal hernia repair in the USA: trends of utilization stratified by surgical volume and consequent impact on perioperative outcomes. J Gastrointest Surg. 2017;21: 1199-205.

Key Words: giant paraesophageal hernia, mesh repair, Collis gastroplasty, surgical approach to giant hiatal hernia, laparoscopy, incarcerated hiatal hernia, fundoplication 